Dear Author,

Please, note that changes made to the HTML content will be added to the article before publication, but are not reflected in this PDF.

Note also that this file should not be used for submitting corrections. 


\title{
Salicylic acid application modulates physiological and hormonal changes in Eucalyptus globulus under water deficit
}

\author{
3 Q1 Cláudia Jesusa ${ }^{\mathrm{a}}$, Mónica Meijón ${ }^{\mathrm{b}, * *}$, Pedro Monteiro ${ }^{\mathrm{a}}$, Barbara Correia ${ }^{\mathrm{a}}$, Joana Amaral ${ }^{\mathrm{a}}$, \\ Mónica Escandón ${ }^{c}$, Maria Jesús Cañal ${ }^{c}$, Glória Pinto ${ }^{a, *}$ \\ ${ }^{a}$ Department of Biology \& CESAM-Centre for Environmental and Marine Studies, University of Aveiro, Campus Universitário de Santiago, 3810-193 Aveiro, \\ Portugal \\ ${ }^{\mathrm{b}}$ Regional Institute for Research and Agro-Food Development in Asturias (SERIDA), “La Mata” Experimental Station, 33820 Grado, Asturias, Spain \\ c Plant Physiology, Dpt. B.O.S., University of Oviedo, 33071 Oviedo, Asturias, Spain
}

\section{A R T I C L E I N F O}

\section{Article history:}

Received 4 March 2015

Received in revised form 27 May 2015

Accepted 5 June 2015

Available online $\mathrm{xxx}$

\section{Keywords:}

Water deficit

Plant performance

Phytohormones crosstalk

Priming

Forest trees

\section{A B S T R A C T}

Eucalyptus genus is the most widely planted hardwood tree, which productivity and development are limited by low water availability. Plant drought tolerance can be managed by adopting strategies, such as the exogenous application of salicylic acid. The main objective of the present study was to assess whether the exogenous foliar salicylic acid application would ameliorate the damages of water deficit on Eucalyptus globulus plants. Plants were watered at 70\% (well water) or 15\% (water deficit) of field capacity and four concentrations of salicylic acid $(0,0.75,2.5$ and $5.0 \mathrm{mM})$ were applied. Water potential, total chlorophylls and carotenoids contents, chlorophyll fluorescence parameters, leaf gas exchange, malondialdehyde, total soluble sugars, starch and total phenols contents were measured. The global hormonal content was quantified by ultra-performance liquid chromatography-mass spectrometry and specific local dynamics of indolacetic acid and abcisic acid were detected by immunolocalization in leaves. A multivariate statistical approach was used to get an overview of the plant physiological status. $E$. globulus water deficit response included growth rate decline associated with reduced in both water potential and leaf gas exchange parameters. Plant water deficit defence strategies led to an increase in total chlorophylls and carotenoids contents, lipid peroxidation, phenols and total soluble sugars. Six from the 18 hormones detected increased in water deficit plants. Exogenous salicylic acid application improved water deficit tolerance of E. globulus by improving water potential with a positive impact in primary metabolism (photosynthetic rate, soluble sugars) but also in secondary metabolism and defence mechanisms (higher total phenols and less lipid peroxidation) in the highest salicylic acid concentrations. Also, changes in endogenous levels of abscisic and salicylic acids, gibberellins 4 and 7 , and specific cytokinins were found in water deficit plants with salicylic acid application. Our results indicated that salicylic acid application could be a potential chemical priming strategy to ameliorate water deficit effects on E. globulus plants.

(c)2015 Elsevier B.V. All rights reserved.

\section{Introduction}

Eucalyptus genus is the most widely planted hardwood tree all over the world (Flynn, 2010) due to the large number of species, wide adaptability to soils and climates, fast-growing rates, the wide knowledge and technology for its culturing and the variety of wood and non-wood products that come from it (Brondani et al., 2012). In Portugal and Spain, E. globulus is the species more

\footnotetext{
* Corresponding author. Fax: +351 234372587.

** Corresponding author.

E-mail addresses: mmeijon@serida.org (M. Meijón),gpinto@ua.pt (G. Pinto).
}

planted, representing approximately 800,000 ha (ICNF, 2013) and 500,000 ha (Potts et al., 2004), respectively.

Drought stress is one of the most important environmental stresses that affects the establishment and limits forest productivity of Eucalyptus plantations (White et al., 2009). Preliminary studies performed by our research group already indicated the detrimental effects of drought conditions in E. globulus plants (decreased water potential, reduced gas exchange rates and stomatal conductance, enhanced lipid peroxidation, among others) and correlated this stress responses with changes in hormonal contents, namely abscisic acid (ABA) and jasmonic acid (JA) (Correia et al., 2014a,b). Understanding how planted forest trees tolerate low water availability, studying new insights to anticipate its impacts and 
implementing new mitigation strategies are essential tasks to undertake in Eucalyptus species in order to sustain productivity and meet future demands for stress-tolerant plant material. Salicylic acid (SA) is a phenolic compound that has been studied as a signal molecule mediating local and systemic defence responses against pathogens (Aimar et al., 2011). This compound was also reported as playing a role in plant responses to abiotic stress, such as drought (Singh and Usha, 2003; Bandurska and Stroinski, 2005; Hayat et al., 2008). The complex SA signalling network has an important role in plant performance by modelling key metabolic and physiological processes. SA influences photosynthesis, increasing photosynthetic rates and leaf area (Khan et al., 2003) and promoting plant growth and yield (Arfan et al., 2007). Plants pre-treated with SA also showed improved relative water content and leaf water potential, reduced electrolyte leakage and decreased level of lipid peroxidation (Hayat et al., 2008). Most of plant responses are regulated by plant hormones that never act individually (Kissoudis et al., 2014). Additive, synergistic or antagonistic interactions between hormonal pathways (Kissoudis et al., 2014) lead to changes in the biological responses for the maintenance of plant stress tolerance (Wang and Irving 2011). Growth and development regulation are essentially coordinated by cytokinins (CKs), auxins (AUXs), gibberellins (GAs), JA, brassinosteroids (BRs), ABA and $\mathrm{SA}$, but the mediating biochemical mechanisms remain largely unknown (Rivas-San Vicente and Plasencia, 2011). Quantifying and monitoring the crosstalk of plant hormonal interactions can, thus, elucidate SAinduced pathways and decipher its role on plant performance. Besides, not always plant responses are successfully correlated with total hormonal content of tissues and knowledge of the precise localization of phytohormones within cell compartments would increase the understanding of its mode of action and its involvement in plant responses (Pastor et al., 1999).

The exogenous application of SA has been considered a shortterm solution to improve the adverse effects of water deficit on plants (Singh and Usha, 2003), however the precise mode of SA action remains unclear (Hayat et al., 2010), in particular for trees. Research on SA application and water deficit tolerance in Eucalyptus species remains completely absent. The existing studies mainly focus on the responses to biotic stress drivers, namely bacteria (Ran et al., 2004) and fungi (Naidoo et al., 2013). Bearing this in mind, the main objective of this work is to investigate whether foliar application of SA can effectively ameliorate the negative effects of water deficit on E. globulus plants and how the plant physiology responds this treatment. Several physiological and biochemical parameters, such as water status, lipid peroxidation, pigments content, total soluble sugars and starch, phenols, $\mathrm{F}_{\mathrm{v}} /$ $\mathrm{F}_{\mathrm{m}}$ and $\phi_{\mathrm{PSII}}$, gas exchange and stomatal conductance, were assessed. We quantified, by ultra-performance liquid chromatography-mass spectrometry (UPLC/MS) and from the same individual sample, the global content of 18 different plant growth regulators. Moreover, changes in indole-3-acetic acid (IAA) and ABA distribution in leaf were visualized by immunolocalization to shed light about the role of these phytohormones in situ in plant mechanism against water deficit after SA application. In order to achieve a global view and a comprehensive picture of the explored plant parameters, PGRs levels, physiological and biochemical parameters were integrated using a multivariate analysis.

\section{Material and methods}

\subsection{Plant material and experimental design}

The experiment was conducted in a controlled climate chamber (Fitoclima 1200 , Aralab, Portugal), with a temperature of $25 / 20^{\circ} \mathrm{C}$, a 16/8-h (day/night) photoperiod and a photosynthetic photon flux density (PPFD) of app. $600 \mu \mathrm{mol} \mathrm{m}^{-2} \mathrm{~s}^{-1}$. Eighty rooted cuttings of one genotype of E. globulus (Al-18) with 2-months-old were obtained from the breeding program of Altri Florestal SA (Portugal). This clone was selected from an open pollination family and first test indicated very good survival results in drought prone areas (Correia et al., 2014a). The rooted cuttings were grown in $1 \mathrm{~L}$ plastic pots filled with $3: 2(\mathrm{w} / \mathrm{w})$ peat:perlite and acclimatized during one-month inside the climate chamber being watered with nutritive solution (N:P:K). The pots were randomly arranged, periodically moved to the neighbouring position during the whole experiment and well-watered to $70 \%$ of field capacity, prior to application of SA. SA was administered to E. globulus plants by foliar spraying with $100 \mathrm{~mL}$ of $0.75,2.5$ and $5.0 \mathrm{mM} \mathrm{SA}$ solution (obtained from preliminary studies) for three consecutive days before the experimental set up. Sodium salicylate (Merck, Darmstadt, Germany) was used to prepare the SA solutions (adjusted to pH 7.0 with $\mathrm{NaOH}$ solution) dissolved in distilled water with the addition of $0.1 \%$ Tween ${ }^{\circledR} 20$ (Sigma-Aldrich, Missouri, USA). Plants treated with $0 \mathrm{mM}$ of SA solution were sprayed with distilled water containing $0.1 \%$ Tween ${ }^{\circledR} 20$. After the last application of SA, half of the plants of each treatment were randomly assigned to each of the two water treatments as follows: (1) well-watered (WW): water supplied every evening until soil water content reached around 70\% field capacity, and (2) water deficit (WD): water supplied every evening until soil water content reached around $15 \%$ field capacity. After two weeks of experiment, the followed parameters were recorded: growth, leaf gas exchange, chlorophyll $a$ fluorescence and water potential. Leaves were harvested, cleaned with a moistened cloth and immediately frozen in liquid nitrogen for further biochemical analysis (estimation of lipid peroxidation, photosynthetic pigments content, total soluble sugars and total phenolic compounds and phytohormones quantification). For further immunolocalization of IAA and ABA, samples sections of leaves were fixed.

\subsection{Growth and plant water potential}

To assess growth, the height of six plants was recorded for each treatment. Midday shoot water potential $\left(\Psi_{\mathrm{md}}\right)$ was measured with a Scholander-type pressure chamber (PMS Instrument Co., OR) in six independent biological replicates per each treatment at $12 \mathrm{~h} 30 \mathrm{~m}$ (solar time) as described by Correia et al. (2014a) in order to control the plant water status.

\subsection{Leaf gas-exchange measurements}

Net $\mathrm{CO}_{2}$ assimilation rate $\left(\mathrm{A}, \mu \mathrm{mol} \mathrm{CO}_{2} \mathrm{~m}^{-2} \mathrm{~s}^{-1}\right)$, stomatal conductance $\left(\mathrm{g}_{\mathrm{s}}, \mathrm{mol} \mathrm{H}_{2} \mathrm{O} \mathrm{m}^{-2} \mathrm{~s}^{-1}\right)$, transpiration rate $(\mathrm{E}, \mathrm{mmol}$ $\mathrm{H}_{2} \mathrm{O} \mathrm{m}^{-2} \mathrm{~s}^{-1}$ ) and intercellular $\mathrm{CO}_{2}$ concentration content $\left(\mathrm{C}_{\mathrm{i}}, \mathrm{ppm}\right)$ were measured in six independent biological replicates per each treatment, using a portable infrared gas analyser (LCpro-SD, ADC BioScientific Ltd., UK) equipped with the broad leaf chamber. To find out the saturation light intensity A/PPFD (photosynthetic photon flux density; light response curves of $\mathrm{CO}_{2}$ assimilation) curves were performed with the following PPFD: 2000,1500,1000, $750,500,250,100,50$ and $0 \mu \mathrm{mol} \mathrm{m}^{-2} \mathrm{~s}^{-1}$. After A/PPFD data analysis, punctual measurements at saturation light intensity were performed at $750 \mu \mathrm{mol} \mathrm{m}{ }^{-2} \mathrm{~s}^{-1}$. The following conditions were maintained inside the chamber during all the measurements: air flux: $200 \mathrm{~mol} \mathrm{~s}^{-1}$; block temperature: $25^{\circ} \mathrm{C}$; and atmospheric $\mathrm{CO}_{2}$ and $\mathrm{H}_{2} \mathrm{O}$ concentration. Data were recorded when the measured parameters were stable (2-6 min).

\subsection{Photosynthetic pigments and chlorophyll a fluorescence analysis}

Total chlorophyll and carotenoid content was quantified according to Sims and Gamon (2002). Pigments were extracted 
with acetone/Tris (50 mM) buffer at pH $7.8(80: 20)(\mathrm{v} / \mathrm{v})$ in six independent biological replicates per each treatment. After homogenization and centrifugation, supernatants were used to read absorbance at 663, 537, 647 and $470 \mathrm{~nm}$ (Thermo Fisher Scientific Spectrophotometer, Genesys 10-uv S) and pigments' content was determined.

Steady-state modulated chlorophyll fluorescence was determined with a portable fluorometer (Mini-PAM; Walz, Effeltrich, Germany) on the same leaves as used for the gas-exchange measurements. Light adapted components of chlorophyll fluorescence were measured: steady-state fluorescence $(F)$, maximal fluorescence $\left(F_{m}^{\prime}\right)$, variable fluorescence $F_{v}$ (equivalent to $F_{m}^{\prime}-F$ ) and quantum yield of PSII photochemistry $\left(\phi_{\text {PSII }}\right)$ equivalent to $\left(F_{m}^{\prime}-F\right) / F_{m}^{\prime}$. Leaves were then dark adapted for at least 20 min to obtain $\mathrm{F}_{0}$ (minimum fluorescence), $\mathrm{F}_{\mathrm{m}}$ (maximum fluorescence), $\mathrm{Fv}$ (variable fluorescence, equivalent to $F_{m}-F_{0}$ ) and $F_{v} / F_{m}$ (maximum quantum yield of PSII photochemistry).

\subsection{Lipid peroxidation, total soluble sugars, starch and total phenolics}

Lipid peroxidation on leaves was estimated using the method described by Correia et al. (2014a), which measures the amount of MDA (malondialdehyde).

Total soluble sugars (TSS) were determined by the anthrone method, as described by Irigoyen et al. (1992). Briefly, TSS were extracted from $50 \mathrm{mg}$ frozen leaves using $80 \%$ (v/v) ethanol at $80^{\circ} \mathrm{C}$ for $1 \mathrm{~h}$. After centrifugation, the supernatant was mixed with $1.5 \mathrm{~mL}$ of anthrone and incubated at $100^{\circ} \mathrm{C}$ during $10 \mathrm{~min}$. Absorbance was read at $625 \mathrm{~nm}$ and TSS content was calculated against a D-glucose standard curve. The pellet resultant from the centrifugation was used to quantify starch, as described by Osaki et al. (1991). The pellet was incubated with $30 \%(\mathrm{v} / \mathrm{v})$ perchloric acid at $60^{\circ} \mathrm{C}$ during $1 \mathrm{~h}$. The mixture was centrifuged and anthrone was added to the supernatant. After heating the mixture at $100^{\circ} \mathrm{C}$ for $10 \mathrm{~min}$, absorbance was read at $625 \mathrm{~nm}$ and starch content was determined according to a D-glucose standard curve.

Total phenolic compounds were determined according to the protocol used by Singleton and Rossi (1965). About $50 \mathrm{mg}$ of frozen plant material were extracted with $80 \%(\mathrm{v} / \mathrm{v})$ cold acetone and the mixture was centrifuged. Folin-Ciocalteu's phenol reagent and $7.5 \%(\mathrm{w} / \mathrm{v})$ sodium carbonate were added to the supernatant and the mixture was kept at room temperature for $30 \mathrm{~min}$. Absorbance was read at $765 \mathrm{~nm}$ and total phenolic concentration was determined according to a gallic acid standard curve. Six biological replicates of each treatment were performed.

\subsection{PGRs quantification}

The analysis of different plant growth regulators (PGRs) (transZeatin, tZ; zeatin riboside, ZR; dihydrozeatin DHZ; dihydrozeatin riboside DHZR; isopentenyl adenine, iP; isopentenyl adenine riboside, iPR; benziladenine, $\mathrm{BA}$; gibberellin $\mathrm{GA}_{3}, \mathrm{GA}_{4}, \mathrm{GA}_{7}$, and, $\mathrm{GA}_{9}$; 24-epibrassinolide, 24EB; Castasterone, BK; 28-homobrassinolide, HBI; JA; SA; ABA; IAA;) was carried out by a modified protocol based on Pan et al. (2008). Briefly, $60 \mathrm{mg}$ of lyophilized tissue were ground into powder and $500 \mu$ l of 2 -propanol $/ \mathrm{H}_{2} \mathrm{O}$ / concentrated $\mathrm{HCl}(2: 1: 0.002, \mathrm{v} / \mathrm{v} / \mathrm{v})$ one deuterated internal standard for each group of phytohormones (10-40 ng) were added, followed by agitation for $30 \mathrm{~min}$ at $4{ }^{\circ} \mathrm{C} . \mathrm{CH}_{2} \mathrm{Cl}_{2}(1 \mathrm{~mL})$ was added, followed by another $30 \mathrm{~min}$ of agitation at $4{ }^{\circ} \mathrm{C}$. Two phases were formed with the plant debris between them. The lower layer was collected, concentrated in $2 \mathrm{~mL}$ glass vials with nitrogen flow and stored until analysis at $-20^{\circ} \mathrm{C}$.

Samples were re-suspended in $200 \mu \mathrm{L}$ of methanol $(\mathrm{MeOH})$ $100 \%$ and filtered through a $0.2 \mu \mathrm{m}$ regenerated cellulose filter (Agilent Technologies) filled with $\mathrm{SiO}_{2}(15 \mathrm{mg})$. All the compounds were separated and quantified by an ultra-high performance liquid chromatography (UHPLC) in a 6460 Triple Quad LC/MS (Agilent Technologies) using the protocol described by Novák et al. (2008). A chromatographic separation was made using a reverse phase column (Zorbax SB-C18 $2.1 \times 50 \mathrm{~mm}$ column). The column was held at $40^{\circ} \mathrm{C}$ and the mobile phase used in the chromatography consisted of (A) 99.9\% $\mathrm{MeOH}$ : $0.1 \% \mathrm{COOH}$ and (B) ammonium formate (10 mM, pH 4). A linear gradient of $\mathrm{MeOH}$, from $10 \%$ to $50 \%$ in $7 \mathrm{~min}$ and reaching 100\% in $2 \mathrm{~min}$, was used to analytical elution. PGRs were quantified by dynamic multireaction monitoring of their $[\mathrm{M}+\mathrm{H}]^{+}$and the appropriate product ions, using optimized cone voltages and collision energies for diagnosis of each PGRs analysed. Three biological replicates of each treatment were performed.

\subsection{Immunolocalization}

To the immunolocalization of IAA and ABA, leaves from $0 \mathrm{mM}$ well-watered (WW) and all water deficit (WD) (0, 0.75, 2.5 and $5.0 \mathrm{mM}$ ) treatments were sampled and immediately fixed according to the method described by Meijón et al. (2010) with some modifications. The tissues were fixed for $24 \mathrm{~h}$ in $3 \%(\mathrm{w} / \mathrm{v})$ paraformaldehyde containing $0.1 \%(\mathrm{v} / \mathrm{v})$ Triton X-100 (SigmaAldrich Co., St. Louis, MO, USA) at $4{ }^{\circ} \mathrm{C}$. To the mixture was also added 4\% (w/v) 1-ethyl-3-(3-dimethylaminopropyl) carbodiimide (Sigma-Aldrich Co., St. Louis, MO, USA) to immobilize IAA and ABA by covalent binding proteins. After $24 \mathrm{~h}$, samples were washed three consecutive times for $10 \mathrm{~min}$ in phosphate-buffered saline [PBS (137 mM NaCl, $2.7 \mathrm{mM} \mathrm{KCl}, 7.9 \mathrm{mM} \mathrm{Na}_{2} \mathrm{HPO}_{4}$ and $1.5 \mathrm{mM}$ $\mathrm{KH}_{2} \mathrm{PO}_{4}$, at $\mathrm{pH}$ 7.3)] to remove the fixing solution. Finally, samples were stored in PBS containing $0.1 \%(\mathrm{w} / \mathrm{v})$ paraformaldehyde at $4^{\circ} \mathrm{C}$. Then, samples were introduced in a cryostat medium (Tissue-Tek, Killik; Sakura Finetek USA, Inc., Torrance, CA, USA) and were frozen at $-23^{\circ} \mathrm{C}$. Finally, sections of $50 \mu \mathrm{m}$ were cut with a sliding cryotome CM1510S (2002 Leica Microsystems, Wetzlar, Germany), collected on slides and conserved at $4{ }^{\circ} \mathrm{C}$ until the analysis. Sections were immersed for $5 \mathrm{~min}$ in ascending and descending 25 , 50, 75 and $100 \%$ ethanol series, washed for $30 \mathrm{~min}$ in PBS containing $0.1 \%(\mathrm{v} / \mathrm{v})$ Tween 20 , and finally for $5 \mathrm{~min}$ in PBS. Before incubating overnight with the ABA or IAA primary antibody (polyclonal Agrisera $A B$, Vännäs, Sweden), samples were pretreated with $5 \%(\mathrm{w} / \mathrm{v}) \mathrm{BSA}$ in PBS for $30 \mathrm{~min}$ to reduce non-specific binding. After washing twice with $0.1 \%(\mathrm{v} / \mathrm{v})$ Tween 20 in PBS for $10 \mathrm{~min}$, sections were incubated with Alexa 488 (Molecular Probes, Göttingen, Germany) as a secondary antibody for $1 \mathrm{~h}$ in darkness. Samples were washed twice for 10 min with $0.1 \%(v / v)$ Tween 20 in PBS. Finally the slides were counterstained with DAPI $\left(4^{\prime}, 6-\right.$ diamidino-2-phenylindole; Fluka). Sections were washed in MilliQ water, and assembled on the slides with Mowiol (Sigma-Aldrich Co., St. Louis, MO, USA). In both immunochemical detection (ABA and IAA) the negative controls were obtained replacing the primary antibody by PBS. Fluorescence was visualized using a confocal microscope (Leica TCS-SP2-AOBS) connected to a workstation and the images were processed with Fiji Software (Schindelin et al., 2012).

\subsection{Statistical analysis}

The results of physiological and biochemical parameters are presented as mean \pm standard deviation (SD) of six independent biological replicates. All statistics procedures were performed using SigmaPlot (SigmaPlot for Windows v. 11.0, Systat Software Inc.). For these parameters two-way analysis of variance (ANOVA) followed by post-hoc multiple comparisons using Holm-Sidak test was employed to estimate the significance of the results $(p \leq 0.05)$. For PGRs quantification, three biological replicates were analysed 
and a Student's t-test was carried out to assess significant differences between WW and WD in non-treated plants. To find out significant differences in the WD plants treated with different SA concentrations, a one-way ANOVA was used, followed by a posthoc Tukey test. In every case, different lowercase letters indicate significant differences between SA concentrations in WW and WD conditions and asterisks indicate significant differences between water treatments $(p \leq 0.05)$.

To reduce the dimensionality and complexity of PGRs data, Heatmap-Clustering was performed normalizing data for each PGR. Principal components analysis (PCA) was carried out to integrate physiological and biochemical data with PGRs profile of $E$. globulus plants by reducing the multivariate data matrix to an interpretable bidimensional biplot that explains the highest proportion of variation of the data (ter Braak and Verdonschot, 1995). SA treatments under WW condition were excluded from PCA because these treatments were not evaluated to global contain of PGRs. Data were a priori centered and normalized to reduce scale effects (ter Braak and Verdonschot, 1995). Heatmap and PCA were conducted using heatmap2 and mixOmics packages with the $\mathrm{R}$ programming language running under the open-source computer software RStudio: Integrated development environment for $\mathrm{R}$ (RStudio Boston, MA. Available on http://www.rstudio.org/).

\section{Results}

\subsection{Growth and plant water status}

Exposure of plants to water deficit led to a general decrease in the height, excepting the plants sprayed with $5.0 \mathrm{mM}$ SA that presented similar height in both water regimes (Table 1 ). Water potential is useful variable to evaluate the physiological water status of plants. In comparison with WW plants, the WD plants showed a significant decrease in the $\psi_{\text {md }}$ values. However, the plants sprayed with SA were significantly less affected than nontreated ones (Fig. 1). Moreover, plants treated with $5.0 \mathrm{mM}$ SA presented the highest water status under water deficit condition (Fig. 1).

\subsection{Chlorophyll and carotenoid quantification and fluorescence}

Under WW condition, plants with and without SA application presented similar values (Table 2). Under water deficit conditions, the total chlorophyll concentration was significantly higher than in well-watered plants, with the exception of the plants sprayed with $5.0 \mathrm{mM}$ SA (Table 2). Moreover, in WD condition, the total chlorophylls tended to decrease with the increasing of SA concentration (Table 2). In the WW condition, after an increase in the carotenoid content at $0.75 \mathrm{mM}$ SA, these compounds diminished as the concentration of SA increased, reaching similar values to the non-treated plants at 2.5 and $5.0 \mathrm{mM}$ (Table 2 ). In the WD plants, carotenoid concentration was significantly lower in the SA-treated plants compared to non SA-treated (Table 2). Regarding

Table 1

Height in well-watered (WW) and water deficit (WD) plants of E. globulus after a two-week water deficit period. Data are presented as mean $\pm \operatorname{SD}(n=6)$. Different lowercase letters indicate significant differences between SA concentrations in WW and WD conditions and asterisks indicate significant differences between water treatments $(p \leq 0.05)$.

\begin{tabular}{lll}
\hline$[\mathrm{SA}](\mathrm{mM})$ & Height $(\mathrm{cm})$ & \\
\cline { 2 - 3 } & WW & WD \\
\hline 0 & $38.27 \pm 2.22 \mathrm{a}$ & $34.50 \pm 0.87 \mathrm{a}^{*}$ \\
0.75 & $41.03 \pm 0.66 \mathrm{a}$ & $35.60 \pm 2.17 \mathrm{a}^{*}$ \\
2.5 & $38.2 \pm 2.08 \mathrm{a}$ & $34.63 \pm 1.97 \mathrm{a}^{*}$ \\
5.0 & $33.45 \pm 1.53 \mathrm{~b}$ & $33.22 \pm 1.46 \mathrm{a}$ \\
\hline
\end{tabular}

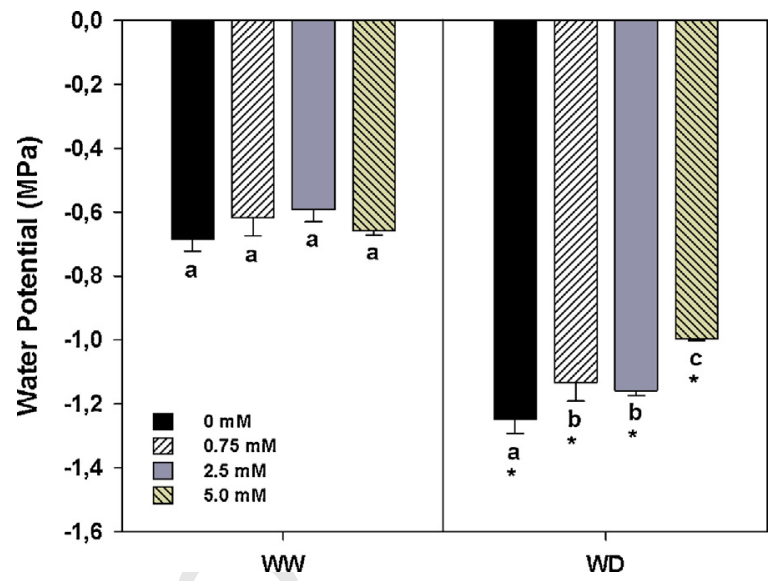

Fig. 1. Midday water potential $\left(\Psi_{\mathrm{md}}\right)$ in well-watered (WW) and water-stressed (WS) plants of E. globulus after a two-week water deficit period. Data are presented as mean $\pm S D(n=6)$. Different lowercase letters indicate significant differences between SA concentrations in WW and WS conditions and asterisks indicate significant differences between water treatments $(p \leq 0.05)$.

the $F_{v} / F_{m}$ (maximum yield of PSII photochemistry) and $\phi_{\text {PSII }}$ (quantum yield of PSII photochemistry) ratios, there were no statistically significant differences between water regimes, neither in plants with or without SA treatment (Table 2).

\subsection{Leaf gas-exchange measurements}

Water deficit reduced net $\mathrm{CO}_{2}$ assimilation rate (A) (Fig. $2 \mathrm{~A}$ ), stomatal conductance $\left(\mathrm{g}_{\mathrm{s}}\right)$ (Fig. 2B), transpiration rate (E) (Fig. 2C) and intercellular $\mathrm{CO}_{2}$ concentration ( $\mathrm{Ci}$ ) (Fig. 2D) of leaves. Under WW condition, SA treatments led to an increase of A and E (Fig. 2A and $C$ ), while $C$ i showed lower values compared to non-treated SA plants (Fig. 2D). Regarding WD condition, A and E increased as the concentration of SA increased, presenting values significantly higher than non-treated plants (Fig. 2A and C).

\subsection{Lipid peroxidation, starch, TSS and total phenolics content}

Lipid peroxidation was measured in terms of MDA concentration. The plants subjected to the water deficit exhibited a significant increase in MDA levels when compared to the WW ones (Fig. 3A). In both cases, the MDA levels decreased as the SA concentration increased (Fig. 3A).

Relatively to starch quantification, no significant differences were observed independently of water treatment and SA application (Fig. 3B). Significant differences in the phenols content were observed in non-treated plants between WW and WD (Fig. 3C). In WW plants, the SA application significantly increased the total phenolics (Fig. 3C). In WD plants, significant differences were observed in 2.5 and $5.0 \mathrm{mM}$ SA, which showed higher levels of phenols compared to 0 and $0.75 \mathrm{mM}$ SA treatments (Fig. 3C).

Relative to TSS content, significant increases were found in plants subjected to WD, except for $5.0 \mathrm{mM}$ SA treatment, which maintained similar values in both water regimes (Fig. 3D).

The accumulation of TSS was significantly higher in plants with SA application both in WW and WD (Fig. 3D). In WW condition, the TSS levels increased as the SA concentration increased. However, in plants subjected to low water availability, the levels of TSS decreased as the SA concentration increased (Fig. 3D).

\subsection{PGRs quantification, IAA and ABA immunolocalization}

For PGRs quantification, we used a highly sensitive and highthroughput method for the simultaneous analysis of 18 molecular 
Table 2

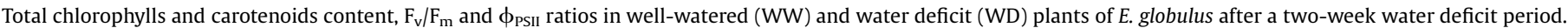

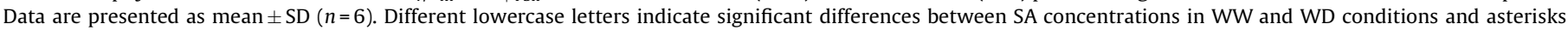
indicate significant differences between water treatments $(p \leq 0.05)$.

\begin{tabular}{|c|c|c|c|c|c|c|c|c|}
\hline \multirow[t]{2}{*}[\mathrm{SA}]{$(\mathrm{mM})$} & \multicolumn{2}{|c|}{ Total Chlorophylls $(a+b)\left(\mu \mathrm{mol} \mathrm{g}^{-1} \mathrm{FW}\right)$} & \multicolumn{2}{|c|}{ Carotenoids $\left(\mu \mathrm{mol} \mathrm{g}^{-1} \mathrm{FW}\right)$} & \multicolumn{2}{|l|}{$\mathrm{F}_{\mathrm{v}} / \mathrm{F}_{\mathrm{m}}$} & \multicolumn{2}{|l|}{$\phi_{\text {PSII }}$} \\
\hline & WW & WD & WW & WD & $\overline{W W}$ & WD & $\overline{W W}$ & WD \\
\hline 0 & $2.33 \pm 0.12 a$ & $3.09 \pm 0.21 a^{*}$ & $0.74 \pm 0.03 \mathrm{ac}$ & $1.03 \pm 0.06 a^{*}$ & $0.84 \pm 0.01 a$ & $0.84 \pm 0.01 a$ & $0.76 \pm 0.03 a$ & $0.78 \pm 0.01 a$ \\
\hline 0.75 & $2.55 \pm 0.18 \mathrm{a}$ & $2.87 \pm 0.11 \mathrm{ab}^{*}$ & $0.83 \pm 0.06 b$ & $0.94 \pm 0.03 b^{*}$ & $0.84 \pm 0.02 \mathrm{a}$ & $0.83 \pm 0.01 \mathrm{a}$ & $0.76 \pm 0.02 \mathrm{a}$ & $0.78 \pm 0.01 a$ \\
\hline 2.5 & $2.39 \pm 0.27 a$ & $2.81 \pm 0.24 \mathrm{ab}^{*}$ & $0.77 \pm 0.06 \mathrm{ab}$ & $0.89 \pm 0.03 b^{*}$ & $0.84 \pm 0.01 a$ & $0.84 \pm 0.01 a$ & $0.79 \pm 0.02 a$ & $0.79 \pm 0.01 a$ \\
\hline 5.0 & $2.65 \pm 0.24 \mathrm{a}$ & $2.63 \pm 0.18 b$ & $0.69 \pm 0.05 c$ & $0.69 \pm 0.05 c$ & $0.84 \pm 0.01 \mathrm{a}$ & $0.84 \pm 0.01 \mathrm{a}$ & $0.78 \pm 0.01 a$ & $0.78 \pm 0.01 a$ \\
\hline
\end{tabular}
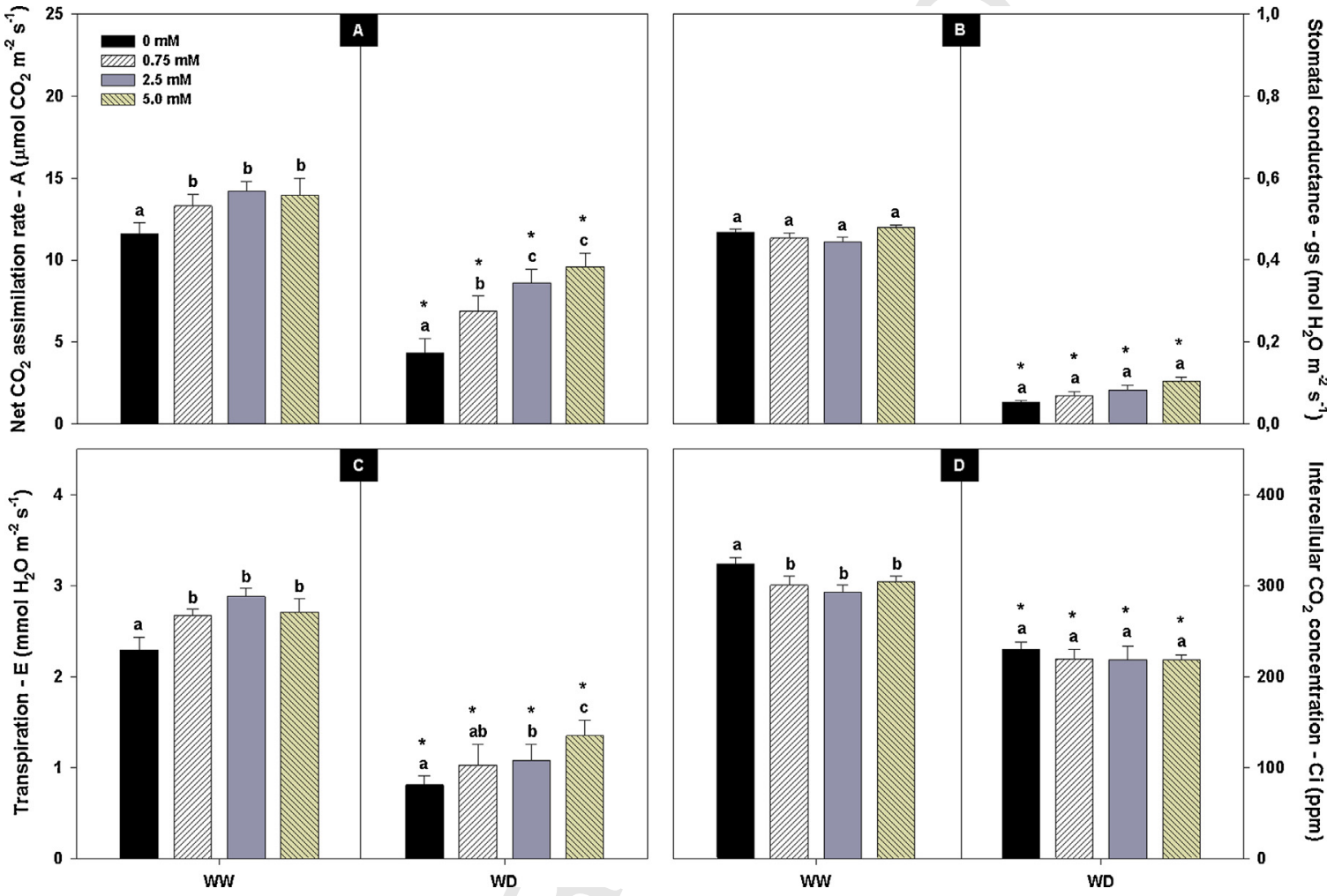

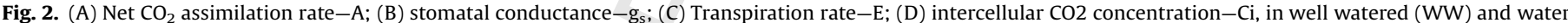

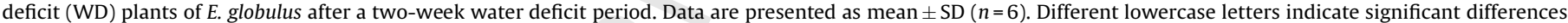
between SA concentrations in WW and WD conditions and asterisks indicate significant differences between water treatments ( $p \leq 0.05)$.

species of CKs, IAA, GAs, JA, BRs, ABA and SA. Plants subjected to WD regime presented higher levels of $A B A$, IAA, JA, iP, GA 4 and $G_{7}$ (Table 3). Additionally, SA treatments influenced ABA, SA, DHZ, iP, $\mathrm{GA}_{4}$ and $\mathrm{GA}_{7}$ amounts. Endogenous ABA content increased linearly with the dose of exogenous SA application, although the differences were only significant between 0.75 and $5.0 \mathrm{mM}$ SA concentrations. Also, SA content increased with the dose of exogenous SA application reaching significant differences at $5.0 \mathrm{mM}$ (Table 3). DHZ (active cytokinin) presented significant higher concentration at $2.5 \mathrm{mM}$ SA, although the differences were only significant in relation to $0.75 \mathrm{mM} \mathrm{SA}$ (Table 3 ). And finally, iP, $\mathrm{GA}_{4}$ and $\mathrm{GA}_{7}$ significantly decreased in most SA treatments (Table 3$)$ in relation to WD control $(0 \mathrm{mM})$. Since the hormonal system represents an intricate network involving functional crosstalk between signalling and metabolism, a comprehensive and integrative analysis of plant hormone changes is required. The global content of the 18 plant hormone-related compounds was represented by heatmap clustering (Fig. 4). Through this representation a clear different hormone profile between WW and WD treatments was shown. Moreover, within WD in SA treatments, it was also observed a differential distribution of the quantified phytohormones species, indicating this specific plant hormone activity not only in relation to water stress but also in relation to SA-doses applied. In the heatmap representation and in relation to phytohormone profile, we observed that 0.75 and $2.5 \mathrm{mM} \mathrm{SA}$ treatment were the treatments closer to $\mathrm{WW}$ plants, while $5.0 \mathrm{mM}$ SA and WD control plants ( $0 \mathrm{mM} \mathrm{SA}$ ) showed greater distance to WW plant in terms of global phytohormone content. Additionally, through immunolocalization studies it was shown that plants response to water deficit induced variation both in concentration and distribution of ABA and IAA. Thereby, under water deficit, ABA signal was unequally distributed and mainly accumulated in vascular tissues, oil glands and epidermis (Fig. 5B). On the other hand, in the WD plants pre-treated with $0.75 \mathrm{mM} \mathrm{SA}$, there was a slight redistribution of ABA into the mesophyll, while with 2.5 and 5.0 mM SA a strong ABA accumulation was observed both around vascular tissues and mesophyll (Fig. 5D and E). Different IAA distribution was also observed under water deficit and SA treatments. In WW plants, IAA signal was mainly located near vascular tissues (Fig. 6A). However, under stress, IAA was equally 

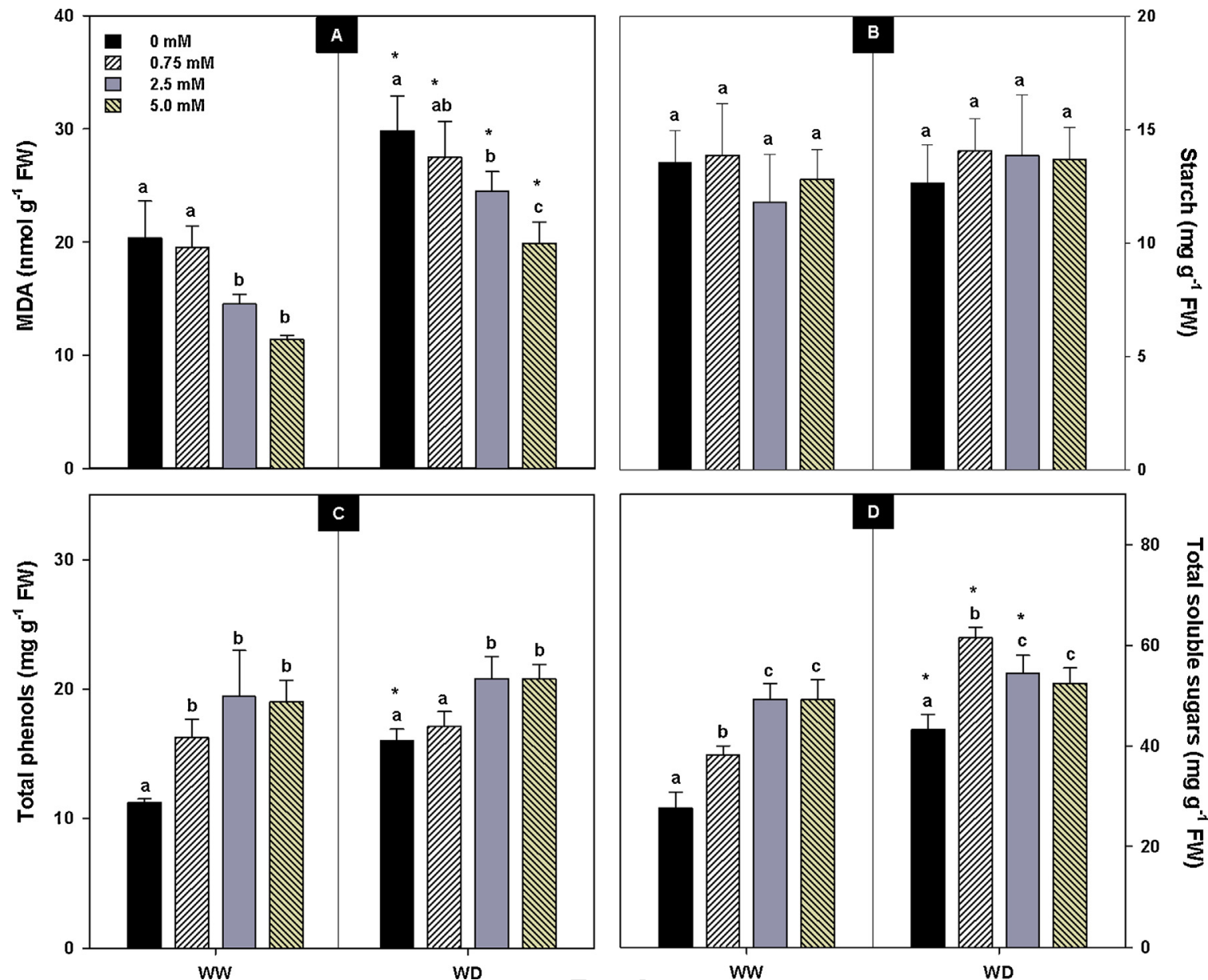

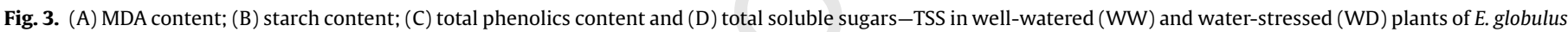

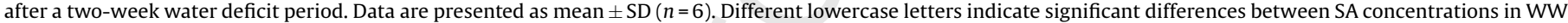
and WD conditions and asterisks indicate significant differences between water treatments $(p \leq 0.05)$.

Table 3

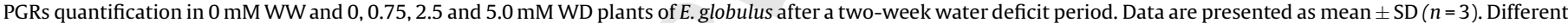

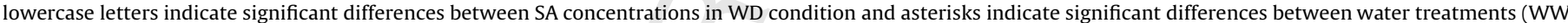
and WD) to $0 \mathrm{mM}(p \leq 0.05)$.

\begin{tabular}{|c|c|c|c|c|c|}
\hline & $0 \mathrm{WW}$ & $0 \mathrm{WS}$ & 0.75 WS & $2.5 \mathrm{WS}$ & $5.0 \mathrm{WS}$ \\
\hline $\mathrm{SA}\left(\mathrm{ng} \mathrm{g}^{-1} \mathrm{DW}\right)$ & $790.9 \pm 554.6$ & $904.0 \pm 323.6 a$ & $806.78 \pm 355.7 a$ & $2079.1 \pm 1184.2 \mathrm{a}$ & $13304.5 \pm 8912.4 b$ \\
\hline $\mathrm{GA}_{3}\left(\mathrm{ng} \mathrm{g}^{-1} \mathrm{DW}\right)$ & $195.5 \pm 101.1$ & $73.7 \pm 53.6 a$ & $214.2 \pm 56.6 a$ & $149.6 \pm 33.4 \mathrm{a}$ & $345.3 \pm 309.3 a$ \\
\hline IAA (ng g $\left.{ }^{-1} \mathrm{DW}\right)$ & $5.6 \pm 0.1$ & $18.5 \pm 3.6 a^{*}$ & $15.8 \pm 10.0 \mathrm{a}$ & $13.9 \pm 2.3 a$ & $28.5 \pm 20.0 \mathrm{a}$ \\
\hline $\mathrm{ABA}\left(\mathrm{ng} \mathrm{g}^{-1} \mathrm{DW}\right)$ & $232.0 \pm 84.6$ & $853.6 \pm 79.8 a^{*}$ & $999.3 \pm 58.2 a$ & $1045.6 \pm 13.9 a b$ & $1205.5 \pm 59.0 \mathrm{~b}$ \\
\hline $\mathrm{JA}\left(\mathrm{ng} \mathrm{g}^{-1} \mathrm{DW}\right)$ & $3.5 \pm 0.3$ & $10.1 \pm 1.39 a^{*}$ & $7.9 \pm 1.0 a$ & $7.9 \pm 2.0 a$ & $8.5 \pm 1.4 a$ \\
\hline $\mathrm{DHZ}\left(\mathrm{ng} \mathrm{g}^{-1} \mathrm{DW}\right)$ & $1.0 \pm 0.2$ & $5.1 \pm 3.0 \mathrm{ab}$ & $1.5 \pm 0.6 \mathrm{a}$ & $6.9 \pm 1.3 b$ & $3.6 \pm 1.5 \mathrm{ab}$ \\
\hline $\mathrm{RDHZ}\left(\mathrm{ng} \mathrm{g}^{-1} \mathrm{DW}\right)$ & $0.8 \pm 0.6$ & $1.6 \pm 0.5 \mathrm{a}$ & $0.6 \pm 0.2 \mathrm{a}$ & $1.4 \pm 0.5 a$ & $1.6 \pm 0.3 a$ \\
\hline $\mathrm{tZ}\left(\mathrm{ng} \mathrm{g}^{-1} \mathrm{DW}\right)$ & $1.89 \pm 0.6$ & $3.0 \pm 1.9 a$ & $1.5 \pm 0.4 a$ & $3.8 \pm 1.7 a$ & $3.9 \pm 1.1 \mathrm{a}$ \\
\hline $\mathrm{GA}_{7}\left(\mathrm{ng} \mathrm{g}^{-1} \mathrm{DW}\right)$ & $21.2 \pm 15.4$ & $90.5 \pm 21.1 a^{*}$ & $20.3 \pm 8.2 b$ & $18.9 \pm 2.8 b$ & $39.9 \pm 35.8 \mathrm{ab}$ \\
\hline $\mathrm{BA}\left(\mathrm{ng} \mathrm{g}^{-1} \mathrm{DW}\right)$ & $7.2 \pm 2.8$ & $15.4 \pm 4.9 a$ & $8.5 \pm 0.6 a$ & $11.6 \pm 2.8 \mathrm{a}$ & $10.1 \pm 3.5 a$ \\
\hline $\mathrm{GA}_{4}\left(\mathrm{ng} \mathrm{g}^{-1} \mathrm{DW}\right)$ & $1356.9 \pm 434.3$ & $3182.7 \pm 994.8 a^{*}$ & $1574.6 \pm 301.5 b$ & $1627.3 \pm 186.5 b$ & $2242.0 \pm 397.2 \mathrm{ab}$ \\
\hline $\mathrm{iP}\left(\mathrm{ngg}^{-1} \mathrm{DW}\right)$ & $2.9 \pm 0.9$ & $10.3 \pm 0.9 a^{*}$ & $5.7 \pm 1.2 \mathrm{~b}$ & $5.4 \pm 0.7 b$ & $5.1 \pm 1.5 b$ \\
\hline $\mathrm{iPA}\left(\mathrm{ng} \mathrm{g}^{-1} \mathrm{DW}\right)$ & $32.3 \pm 17.3$ & $53.6 \pm 20.7 a$ & $30.4 \pm 19.3 a$ & $26.9 \pm 1.9 a$ & $21.3 \pm 18.4 a$ \\
\hline 24EB $\left(\mathrm{ng} \mathrm{g}^{-1} \mathrm{DW}\right)$ & $1192.5 \pm 415.8$ & $877.1 \pm 347.5 a$ & $307.8 \pm 35.1 \mathrm{a}$ & $668.7 \pm 394.6 a$ & $676.4 \pm 274.3 a$ \\
\hline HBI $\left(\operatorname{ng~g}^{-1} \mathrm{DW}\right)$ & $24.7 \pm 9.1$ & $24.9 \pm 15.2 \mathrm{a}$ & $9.6 \pm 2.5 a$ & $12.2 \pm 9.2 \mathrm{a}$ & $16.7 \pm 13.4 \mathrm{a}$ \\
\hline $\mathrm{RZ}\left(\mathrm{ng} \mathrm{g}^{-1} \mathrm{DW}\right)$ & $23.9 \pm 6.9$ & $20.6 \pm 10.0 a$ & $28.5 \pm 10.7 a$ & $25.4 \pm 7.7 a$ & $26.4 \pm 14.7 a$ \\
\hline $\mathrm{GA}_{9}\left(\mathrm{ng} \mathrm{g}^{-1} \mathrm{DW}\right)$ & $89.5 \pm 21.5$ & $91.4 \pm 39.9 a$ & $82.4 \pm 46.1 a$ & $61.4 \pm 23.3 a$ & $76.1 \pm 37.1 \mathrm{a}$ \\
\hline $\mathrm{BK}\left(\mathrm{ng} \mathrm{g}^{-1} \mathrm{DW}\right)$ & $2285.5 \pm 695.9$ & $2029.6 \pm 370.4 a$ & $1641.1 \pm 1262.9 \mathrm{a}$ & $1471.6 \pm 240.2 a$ & $1902.2 \pm 171.3 a$ \\
\hline
\end{tabular}

accumulated around all the leaf-tissues (Fig. 6B). Differences on IAA accumulation between non-treated and SA treated plants were less clear (Fig. 6B-E). However, at the higher SA concentration a special accumulation can be noticed (Fig. 6E), which was in accordance with IAA global quantification by LC-MS methodology.
3.6. Multivariate approach: global overview of physiological status

PCA ordination provided an overall picture of the physiological/ biochemical condition of E. globulus plants during the experimental setup, revealing a clear separation between water regime and 


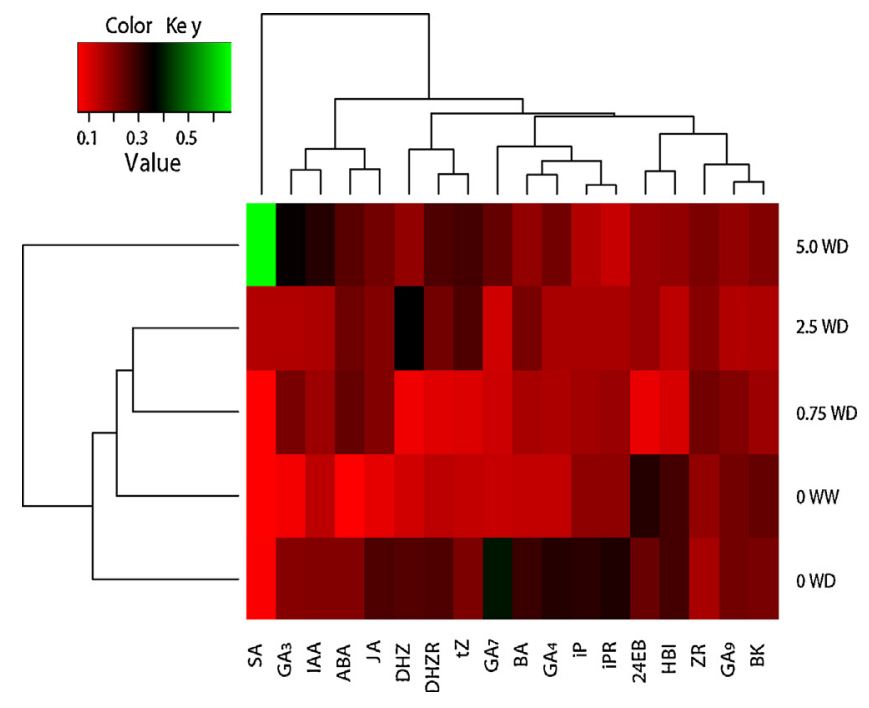

Fig. 4. Heatmap of PGRs content in $0 \mathrm{mM}$ WW and $0,0.75,2.5$ and $5.0 \mathrm{mM}$ WD plants of E. globulus after a two-week water deficit period. The relative accumulation patterns are shown in the heat map based on the average value $(n=3)$ for each plant hormone. Red and green colours indicate lower and higher concentrations, respectively. The colour scale is shown at the top.

SA application (Fig. 7). Non treated well watered plants (0 WW) were grouped together (Fig. 7, left side) suggesting homogeneity in the physiology and biochemistry of plants in non-stressful conditions. Sample scores of WD plants were all located on the right side, with the plants that were not pre-treated with SA (OWD) being located in the upper right part (Fig. 7). The horizontal left-to-right movement observed in WD is mostly explained by lower $\mathrm{Ci}$, gs, E, water potential, and height and higher JA, IAA, MDA, and total chlorophyll compared to WW (Fig. 7). SA treated WD scores progressively moved from top-to-bottom (Fig. 7). The downwards migration pattern of PCA scores under increased SA treatment is most probably associated with vertical gradients, such as increased ABA, SA, TSS, and total phenols and decreased IP, GA and carotenoids (Fig. 7).

\section{Discussion}

\subsection{Water deficit effect in $\mathrm{E}$. globulus}

Impaired plant growth and development are the first and most concerning effects of low water availability in plants. In fact, water stressed plants of $E$. globulus showed a marked reduction in height (Table 1), which is in agreement with other reports (Silva et al., 2004; Granda et al., 2011; Correia et al., 2014a). Cell growth is mainly affected by a reduction in turgor pressure and decreased $\mathrm{CO}_{2}$ diffusion from atmosphere (Pinheiro and Chaves 2011). Following this assumption, WD plants showed decreased water potential values (Fig. 1), as already documented in other works (Guarnaschelli et al., 2006; Correia et al., 2014a), as well as $\mathrm{Ci}, \mathrm{CO}_{2}$ assimilation, $\mathrm{g}_{\mathrm{s}}$ and $\mathrm{E}$ (Fig. 2). Stomatal limitation under water deficit conditions is accepted as one of the main limitations of plant photosynthesis and further productivity (Silim et al., 2009) and it has been well documented (Bogeat-Triboulot et al., 2007; Ditmarová et al., 2009). Maximum and effective PSII photochemistry performance, assessed as $\mathrm{F}_{\mathrm{v}} / \mathrm{F}_{\mathrm{m}}$ and $\phi_{\text {PSII }}$, respectively, was not negatively affected in response to water deficit (Table 2) however, according to Correia et al. (2014a), total chlorophylls and carotenoids increased with WD (Table 2). As argued, the increasing chlorophyll content could be related to a reduction in leaf mass expansion and to a protective role of carotenoids or other mechanisms, which protected these pigments from degradation and preserve the photosynthetic capacity. The peroxidation of lipids is the most obvious symptom of oxidative stress in plants. Drought induced oxidative stress leads to the generation of reactive oxygen species (ROS). The prevalence of free radicals reaction in membranes is indicated by the accumulation of MDA (Fig. 3A), which is expected to show greater accumulation under environmental stresses (Cakmak and Horst, 1991; Xu and Zhou, 2006). Another response to oxidative stress is the accumulation of polyphenols (Fig. 3C). These compounds possess ideal structural chemistry for free radical scavenging activities (Rice-Evans et al., 1997) and are reported as accumulating in several abiotic stresses (Alexieva et al., 2001; Rivero et al., 2009). Total soluble sugars content (Fig. 3D) rose in response to water deficit. This is a common response in water deficit stress considering that accumulation of compatible solutes is an important physiological adaptation and enables osmotic adjustment including in eucalypts plants (Parida et al., 2007; Mohammadkhani and Heidari, 2008). In fact, soluble sugars do not only function as metabolic resources and structural constituents of cells, they also act as signals and interact with stress pathways into a complex network to modulate metabolic plant responses (Rosa et al., 2009). Plant hormones are essential molecules able to modify plant physiology and biochemistry in rapid response to changes in their environment, a critical requirement for their survival as sessile organisms. Morphophysiological responses as growth reduction or stomatal closure (among others) under water deficit are outcomes regulated by a complex network of hormone signalling pathways. The major and the best-known player, ABA, acts in concert with jasmonates, ethylene, AUXs, and CKs (Nemhauser et al., 2006; Huang et al., 2008). From the studied hormones, ABA, IAA, JA, iP, GA 4 , and $\mathrm{GA}_{7}$ increased under water deficit conditions (Table 3 ). ABA is considered a key hormone in the response to drought stress (Zhang et al., 2006) and in E. globulus has been shown to form part of a complex signalling network which mediates the physiological changes induced by drought stress (Granda et al., 2011). Correia et al. (2014a,b) also found higher ABA accumulation in the leaves of E. globulus during drought stress, being in accordance with the defined signalling role of ABA under water deficit conditions (Galmés et al., 2007; Jiang and Hartung, 2008). Regarding JA and its metabolically active derivatives (jasmonates), there is increasing evidence that they are also crucial signalling molecules involved in many plant responses to biotic and abiotic stresses (Brossa et al., 2011). In our work, ABA and JA hormones seem to have a synergistic interaction in response to water deficit stress, which is according to other studies (Fujita et al., 2006; Harb et al., 2010; Brossa et al., 2011). JA may interact with ABA synthesis under water deficit conditions (Bandurska et al., 2003) and this interaction could regulate stomatal closure (Acharya and Assmann, 2009). Our results also showed an increase on IAA content in plants subjected to water deficit, which explained that under moderate osmotic stress IAA promotes water uptake into the protoplasts (Pustovoitova et al., 2003). IAA and ABA are probably involved in turn in the process of drought adaptation and perform phase-specific functions (Pustovoitova et al., 2003). In fact, IAA is considered for some authors as the most representative 'water deficit signal' (De Diego et al., 2012). De Diego et al. (2013) also confirmed the efficiency of immunolocalization techniques as a tool to understand the translocation of IAA and ABA in plants subjected to different water stress situations. In our study, the immunolocalization of ABA and IAA concurred with the global quantification results showing an accumulation under water deficit conditions of these hormones (Figs. 5 and 6). Additionally, the immunolocalization data indicated that eucalypts response to water deficit also induced a variation in ABA and IAA distribution. Thus, we observed that under water deficit $A B A$ is mainly translated into the tissues 

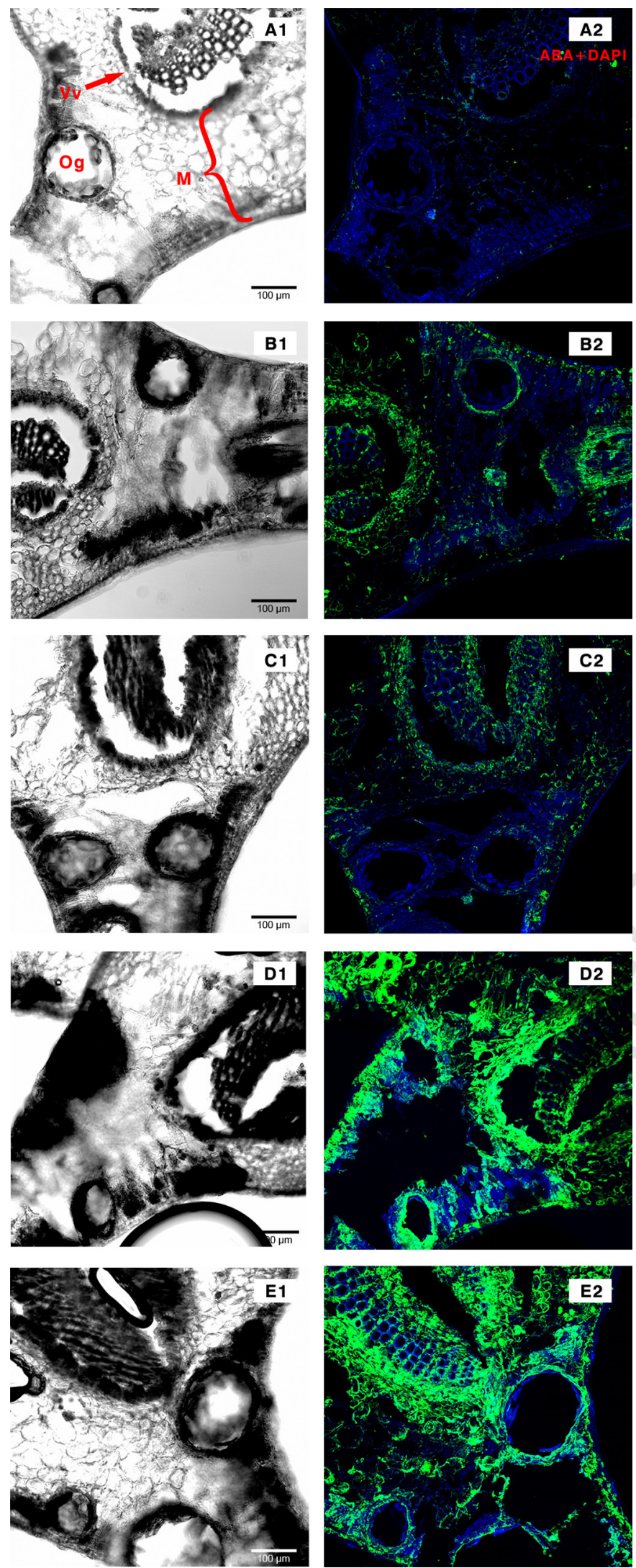

Fig. 5. Immunodetection of $A B A$ in section of $E$. globulus leaves using confocal microscope. Differential interference contrast (DIC) (A1, B1, C1, D1 and E1) and immunolocalization of ABA (A2, B2, C2, D2 and E2). ABA labelling: DAPI (blue signals) and $A B A$ (Green signals) merged in transversal leaf section. (A1 and 2 ) -0 mM WW; (B1 and 2) -0 mM WD; (C1 and 2) $-0.75 \mathrm{mM} \mathrm{WD}$; (D1 and 2) $-2.5 \mathrm{mM}$ WD; (E1 and 2) -5.0 mM WD. Abbreviations: Vv= Vascular vessels; $\mathrm{M}=$ Mesophyll; $\mathrm{Og}=$ Oil gland. Three biological replicates of each treatment were performed.
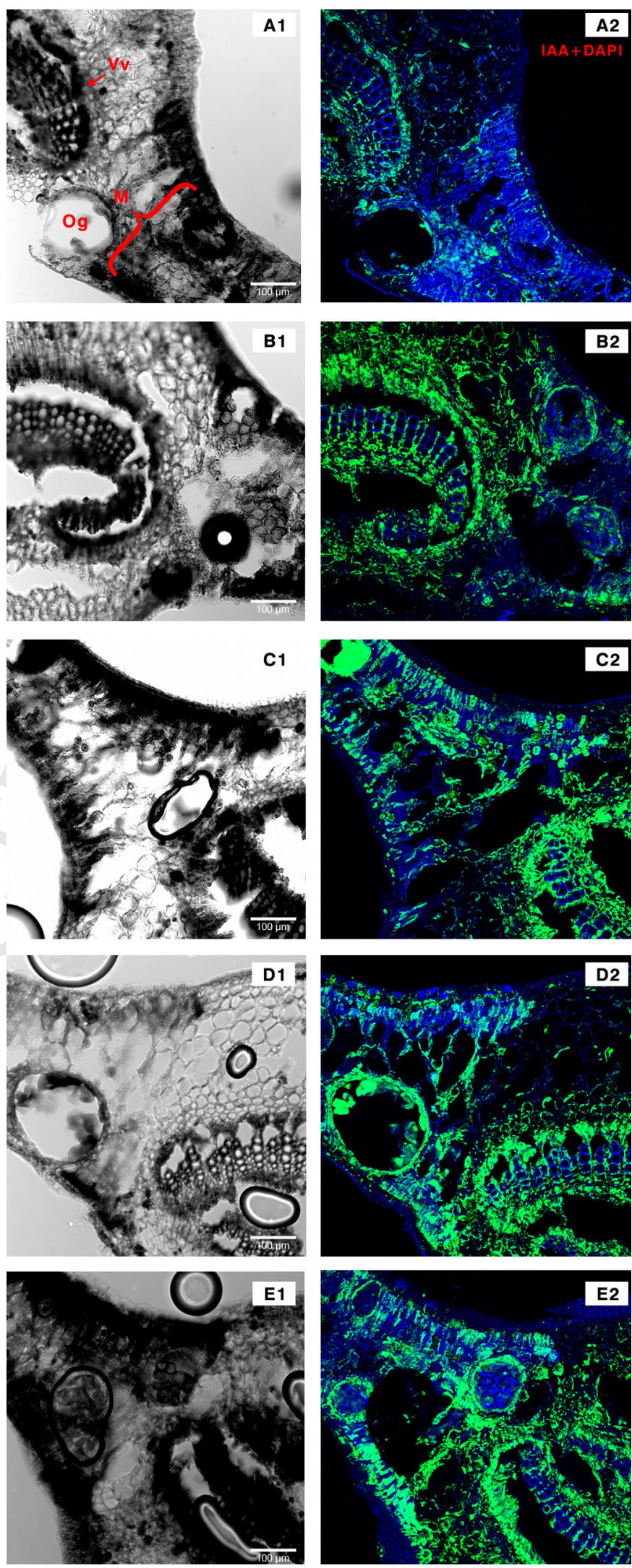

Fig. 6. Imnunodetection of IAA in section of $E$ globulus leaves using confoca microscope. Differential interference contrast (DIC) (A1, B1, C1, D1 and E1) and immunolocalization of IAA (A2, B2, C2, D2 and E2). IAA labelling: DAPI (blue signals) and IAA (Green signals) merged in transversal leaf section. (A1 and 2) $-0 \mathrm{mM} \mathrm{WW}$ (B1 and 2) $-0 \mathrm{mM} \mathrm{WD;} \mathrm{(C1} \mathrm{and} \mathrm{2)}-0.75 \mathrm{mM} \mathrm{WD;} \mathrm{(D1} \mathrm{and} \mathrm{2)}-2.5 \mathrm{mM} \mathrm{WD;} \mathrm{(E1} \mathrm{and}$ 2) $-5.0 \mathrm{mM}$ WD. Abbreviations: $\mathrm{Vv}=$ Vascular vessels; $\mathrm{M}=$ Mesophyll; Og=Oil gland. Three biological replicates of each treatment were performed. 


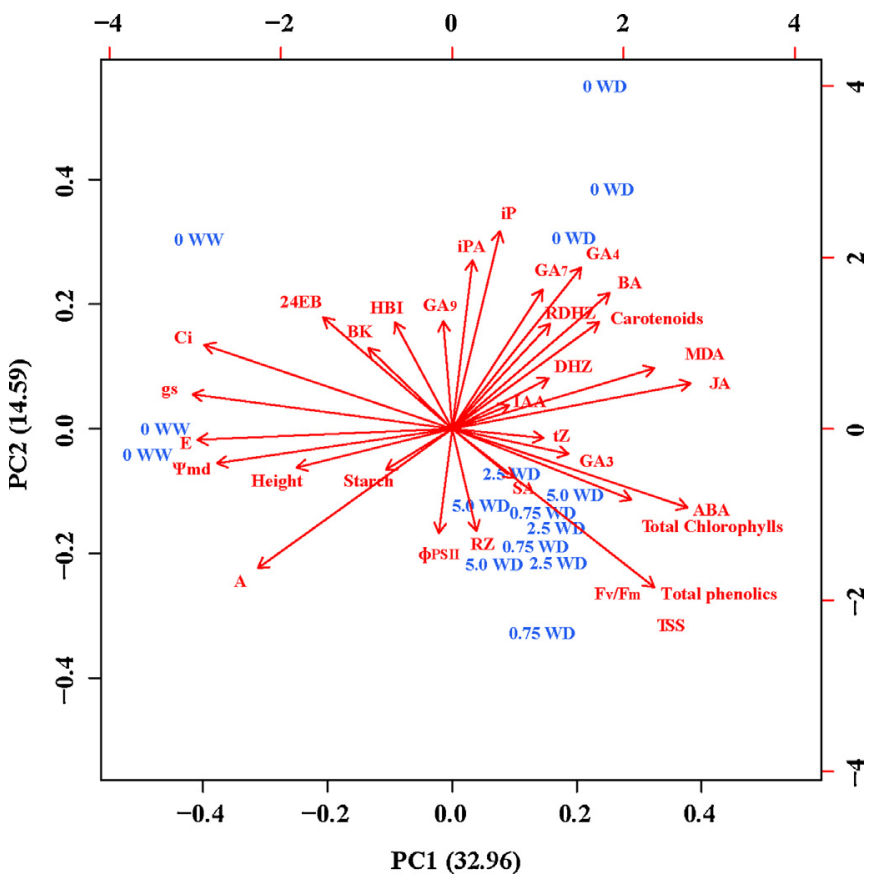

Fig. 7. PCA biplot of the physiological data of Eucalyptus globulus plants in theexperimental setup. Squares areas were used to highlight the position specific stress ( 0 WW plants; 0 WD plants and $0.75,2.5$ and $5.0 \mathrm{mM} \mathrm{WD)}$ ). Loading plots for the first axis (explained variation is $32.96 \%$ ) and second axis (explained variation is $14.59 \%)$.

that are more in contact with the external environment (vascular tissues, oil glands and epidermis) while IAA is indifferently translocated into all the tissues of the leaf. The rapid mobilization of IAA could be related to the fact that IAA changes are frequently due to crosstalk with other hormones (Chandler, 2009) especially with CKs, other essential hormone to plant response to stress. It is well established that CKs can regulate several processes of plant growth and development, including the response of plant to abiotic stress (Pospíšilová et al., 2000). It has been described that CKs play an important role in the development of the plant photosynthetic apparatus by directly affecting the chloroplast and reducing chlorophyll degradation (Rivero et al., 2010). In fact, according Dwivedi et al. (2014) the increase of the total chlorophyll content observed in our data could also be directly related to the higher level of iP hormone observed in WD plants. Moreover, CKs may partially ameliorate negative effects of water stress by stimulating osmotic adjustment (Merewitz et al., 2012), such as increasing carbohydrate content (Sarafraz-Ardakani et al., 2014), and directly or indirectly scavenging ROS (Stoparić and Maksimović, 2008). Last but not least, a classical growth hormones, the GAs $\left(\mathrm{GA}_{4}\right.$ is one of the predominant bioactive forms) are crucial targets for stress-induced growth modulation and there is increasing evidence for their involvement in growth regulation under particular abiotic stress (Colebrook et al., 2014). There are relatively little published studies on the influence of water deficit on GA metabolism and crosstalk with other hormones. In our study $\mathrm{GA}_{4}$ and $\mathrm{GA}_{7}$ act in synergy with $\mathrm{ABA}$ unlike most of the reports (Colebrook et al., 2014). As far as we know, this is the first report where such complete quantification of hormones, as well as immunolocalization of ABA and IAA was performed for E. globulus exposed to water deficit.

\subsection{Foliar application of SA and water deficit tolerance}

At the morphological level, all SA pre-treated plants showed necrotic leaf lesions in leaves due to direct contact to SA, which was not transported into the tissue (Bandurska and Stroinski, 2005), being more evident in the highest concentration.. In general, the foliar application of the phenolic compound: SA ameliorated the negative damages of water deficit. SA application alleviated water potential in WD plants to a great extent, without affecting WW plants (Fig. 1). This response was enhanced according to the higher concentrations of SA.). In parallel, the studied compatible solutes, TSS, also increased in response to SA application (Fig. 3D). The strong correlation between accumulation of compatible solutes and water relation components indicates the involvement of those solutes to balance plant water status under drought (Faroog et al., 2009). Total phenols levels similarly increased in response to SA treatment (Fig. 3C). This increase may also be part of the explanation to the lower levels of MDA in SA-treated WW and WD plants (Fig. 3A). Our results support that the decreased membrane damage may be related with the induction of antioxidant responses triggered by SA, including soluble sugars and phenols accumulation, which in turn protect plants against ROS and membrane injury or may affect synthesis of other substances, having a protective effect on plants under stress (Bandurska and Stroinski 2005). Fayez and Bazaid (2014) showed that SA application alleviate lipid peroxidation in barley plants in contrast to the untreated plants under drought stress condition. Carotenoids in WW and WD plants decreased when treated with SA (Table 2) reflecting stress relief as they play a critical role in preventing photo-oxidative damage. Although the total chlorophylls in WW plants was similar between non-treated and SA treated plants, in WD plants a pronounced response occurred due to the SA application. As argued before, water deficit induced the increase of these pigments in E. globulus. Thus, we defend that SA application could alleviate the water deficit effects on chlorophylls content. As SA induced water deficit relief, a reduction in leaf mass expansion and the protective role of carotenoids or other mechanisms to protect the chlorophylls from degradation and preserve the photosynthetic capacity was not necessary. Bearing this in mind, the application of SA caused an increase in $\mathrm{A}$ and $\mathrm{E}$ (Fig. 2A and C), slightly induced gs (Fig. 2B) and did not change $\mathrm{Ci}$ (Fig. 2D) on E. globulus. The observed increase between $A$ and gs in this study partly support Galmés et al. (2007), suggesting that SAinduced photosynthesis may depend on stomatal control. Furthermore, and as explained above, SA is probably inducing several nonstomatal responses, preventing major metabolic impairment and carboxylase inactivation of RuBisCO. It is possible that SA-induced an increase in RuBisCO activity, which could be responsible for the increase in the photosynthetic rate, as it has been previously described by Singh and Usha (2003) for wheat plants. Understanding the complicity of plant hormone cross-linking networks is important to unravel how plants adapt to environmental changes. In this work, we could observe that SA application increased $\mathrm{SA}, \mathrm{ABA}$ and $\mathrm{DHZ}$ and decreased $\mathrm{GA}_{4}, \mathrm{GA}_{7}$ and iP levels. Other works also showed that through PGR exogenous application not only plant physiology is altered but also the general hormone status of the plant (Meijón et al., 2011a). As expected, SA concentration also drastically increased with SA application (Table 3 ) demonstrating the effective exogenous absorption of SA by the eucalypts plants. However, the treatments of plants with SA also caused a clear increase of ABA content and redistribution in E. globulus leaves tissues in relation to SA-doses applied. So, with the increase of the SA concentration, ABA is expanded along all the leaf tissues. Bandurska and Stroinski (2005) defended that the increased ABA levels after SA application and before drought stress imposition may be responsible for the alleviation of membrane injury in barley plants when subjected to drought stress. Shakirova et al. (2003) also argued that the SA-induced increase in ABA might contribute to a pre-adaptation of wheat plants to stress. According with the authors, ABA serves as an intermediate in the sign of the 
protective action of SA. SA-treatment induced a higher accumulation of $A B A$, which in turn induces a wide spectrum of anti-stress programs in the plants. On the other hand, the negative correlation between iP and DHZ under SA treatment could imply a displacement of the $\mathrm{CK}$ biosynthesis route in relation to the decrease of growth and cell division (Table 1). iP is the initial precursor of CKs biosynthesis and by means of side-chain transhydroxylation reactions is converted in DHZ, very active CK. The large increase in free bases of the Z-type species is related to the activity of CKs (Meijón et al., 2011a,b). Experiments have shown that the free form of Z-type species, but not its derivative riboside or ribotide, binds directly to the receptor CYTOKININ RESPONSE 1 (CRE1) (Yamada et al., 2001), indicating that the free base is the only active form of this CK. Furthermore, the decrease on iP could also be related to the lower level of total chlorophyll content verified on WD plants treated by SA, as previously explained. The reduction in $\mathrm{GA}_{4}$ and $\mathrm{GA}_{7}$ (Table 3 ) was expected as a correlation between $S A$ treatment and inhibition gibberellin synthesis. Xie et al. (2007) showed that SA suppressed GA-induced expression in barley.

The clear distribution revealed by PCA-analysis (Fig. 7) came upon the previously described results providing an overview of the all data obtained in this work. First, the horizontal gradient (PC1) revealed a well-defined separation between WW and WD. Component 1 is mainly supported by the decrease in height, gas exchange and water potential, the most sensitive physiological evidence of water deficit, as previously explained. Besides, the water deficit was also marked by increased lipid peroxidation, chlorophylls, JA and IAA, which are also known responses after water deficit imposition. On the other hand, the effect of SA application is highlighted by the vertical gradient (PC2). Through the loadings of component 2 it is revealed that SA increase could be linked to an increase in total phenols and TSS, which in turn seem to be related to a biased MDA decrease and $\mathrm{CO}_{2}$ assimilation increase. Additionally, by component 2 heft, it is again confirmed that SA response to water stress in eucalypts plants is also connected to ABA stress response.

\section{Conclusions}

Our results show that WD generally affected E. globulus performance but the pre-treatment with exogenous SA increased the tolerance of these plants to low availability water. SA application ameliorated the damaging effects of water deficit on E. globulus, probably by inducing different anti-stress programs that were expressed by improving some physiological and biochemical attributes. The complicity of plant hormone crosslinking networks makes extremely difficult to study individual role of each phytohormone in specific physiological processes. However, through this work, we could demonstrate that by combining uni- and multivariate statistical approaches, despite of the complex PGRs response to drought, it is possible to get an overview of PGRs dynamics in water deficit response of eucalypts plants. We proved that the efficiency of exogenous SA action depend on the SA concentrations getting the best result in the plants treated with higher SA concentrations. Various strategies can be considered to maximize Eucalyptus productivity and water use efficiency under environmental stress such as drought. A fundamental one is to develop drought-tolerant plants through genetic means (by genetic engineering or conventional breeding). However such processes are very time consuming. An alternative and technical simpler approach with short-term results is to induce drought tolerance through exogenous application of compounds such as SA. In practice this investment can be adopted in nurseries production management and initial field establishment to improve plant quality, maintaining healthy trees that is important for ensuring future sustainability of the forestry industry. Here, we are able to conclude that foliar application of SA could be used as a potential chemical priming strategy in $E$. globulus.

\section{Uncited references}

Bidabadi et al. (2012), Brady and McCourt (2003), Guidi and Calatayud (2014), Iglesias and Wilstermann (2008), Mishra and Prakash (2014), Pila et al. (2010) and Volker and Greave (2005).

\section{Acknowledgments}

The authors extend thanks to Armando Costa (University of Aveiro, Portugal) for help with experimental set up, Luis Valledor (University of Oviedo) for statistical advance, Carolina de la Torre and Isabel Feito (SERIDA, Spain) for their assistant support in phytohormone extraction. This research was supported by FEDER through COMPETE (Programa Operacional Fatores de Competitividade), by the FCT project PTDC/AGR-CFL/112996/2009 and by UID/AMB/50017/2013. FCT supported the fellowship of B Correia (SFRH/BD/86448/2012) and G Pinto (SFRH/BPD/101669/2014). M Meijón is funded by Juan de la Cierva Programme (JCI-2011-08958) (Spanish Ministry of Economy and Competitiviness) and $\mathrm{M}$. Escandón fellowship was supported by Severo Ochoa Programme (BP11117) (Gobierno del Principado de Asturias, Spain).

\section{References}

Acharya, B.R., Assmann, S.M., 2009. Hormone interactions in stomatal function Plant Mol. Biol. 69, 451-462.

Aimar, D., Calafat, M., Andrade, A., Carassay, L., Abdala, G., Molas, M., 2011. Drought tolerance and stress hormones: from model organisms to forage crops. Plants Environ. 137-164.

Alexieva, V., Sergiev, I., Mapelli, S., Karanov, E., 2001. The effect of drought and ultraviolet radiation on growth and stress markers in pea and wheat. Plant Cell Environ. 24, 1337-1344.

Arfan, M., Athar, H.R., Ashraf, M., 2007. Does exogenous application of salicylic acid through the rooting medium modulate growth and photosynthetic capacity in two differently adapted spring wheat cultivars under salt stress. J. Plant Physiol. $164,685-694$.

Bandurska, H., Stroinski, A., 2005. The effect of salicylic acid on barley response to water deficit. Acta Physiol. Plant. 27, 379-386.

Bandurska, H., Stroiński, A., Kubiś, J., 2003. The effect of jasmonic acid on the accumulation of ABA, proline and spermidine and its influence on membrane injury under water deficit in two barley genotypes. Acta Physiol. Plant. 25, 279285.

Bidabadi S.S., Mahmood M., Baninasab B., Ghobadi C. (2012) Influence of salicylic acid on morphological and physiological responses of banana (Musa acuminata cv.'Berangan', AAA) shoot tips to in vitro water stress induced by polyethylene glycol. Plant OMICS: Journal of Plant Molecular Biology \& Omics. 5.

Bogeat-Triboulot, M.-B., Brosché, M., Renaut, J., Jouve, L., 2007. Gradual soil water depletion results in reversible changes of gene expression, protein profiles, ecophysiology, and growth performance in Populus euphratica, a poplar growing in arid regions. Plant Physiol. 143, 876-892.

Brady, S., McCourt, P., 2003. Hormone cross-talk in seed dormancy. J. Plant Growth Regul. 22, 25-31.

Brondani, G.E., Wendling, I., Brondani, A.E., Araujo, M.A., Silva, A.L.L., Gonçalves, A N., 2012. Dynamics of adventitious rooting in mini-cuttings of Eucalyptus benthamii $\times$ Eucalyptus dunnii. Acta Sci. Agron. 34, 169-178.

Brossa, R., López-Carbonell, M., Jubany-Marí, T., Alegre, L., 2011. Interplay between abscisic acid and jasmonic acid and its role in water-oxidative stress in wildtype, ABA-deficient, JA-deficient, and ascorbate-deficient Arabidopsis plants. J. Plant Growth Regul. 30, 322-333.

Cakmak, I., Horst, W., 1991. Effect of aluminium on lipid peroxidation, superoxide dismutase, catalase, and peroxidase activities in root tips of soybean (Glycine max). Physiol. Plant. 83, 463-468.

Chandler, J., 2009. Auxin as compère in plant hormone crosstalk. Planta 231, 1-12.

Colebrook, E., Thomas, S., Phillips, A., Hedden, P., 2014. The role of gibberellin signalling in plant responses to abiotic stress. J. Exp. Biol. 217, 67-75.

Correia, B., Pintó-Marijuan, M., Neves, L., Brossa, R., Dias, M.C., Costa, A., Castro, B.B., Araujo, C., Santos, C., Chaves, M.M., Pinto, G., 2014a. Water stress and recovery in the performance of two Eucalyptus globulus clones: physiological and biochemical profiles. Physiol. Plant. 150, 580-592.

Correia, B., Pintó-Marijuan, M., Castro, B., Brossa, R., López-Carbonell, M., Pinto, G. 2014b. Hormonal dynamics during recovery from drought in two Eucalyptus globulus genotypes: from root to leaf. Plant Physiol. Biochem. 82, 151-160. 
De Diego, N., Pérez-Alfocea, F., Cantero, E., Lacuesta, M., Moncaleán, P., 2012. Physiological response to drought in radiata pine: phytohormone implication at leaf level. Tree Physiol. 32, 435-449.

De Diego, N., Rodríguez, J., Dodd, I., Pérez-Alfocea, F., Moncaleán, P., Lacuesta, M. 2013. Immunolocalization of IAA and ABA in roots and needles of radiata pine (Pinus radiata) during drought and rewatering. Tree Physiol. 33, 537-549.

Ditmarová, L'., Kurjak, D., Palmroth, S., Kmeť, J., Střelcová, K., 2009. Physiological responses of Norway spruce (Picea abies) seedlings to drought stress. Tree Physiol. tpp116.

Dwivedi, S., Kumar, S., Mondal, S., Malviya, N., Dubey, R., 2014. Physiological Basis of cytokinin induced drought tolerance in wheat (Triticum aestivum L.). J. AgriSearch 1.

Farooq, M., Basra, S.M.A., Wahid, A., Ahmad, N., Saleem, B.A., 2009. Improving the drought tolerance in rice (Oryza sativa L.) by exogenous application of salicylic acid. J. Agron. Crop Sci. 195, 237-246.

Fayez, K., Bazaid, S., 2014. Improving drought and salinity tolerance in barley by application of salicylic acid and potassium nitrate. J. Saudi Soc. Agric. Sci. 13, 45-

Flynn, B., 2010. Eucalyptus: having an impact on the global solid wood industry. Wood Resources International. http://wwwwri-ltdcom/marketPDFs/ Eucalyptuspdf.

Fujita, M., Fujita, Y., Noutoshi, Y., Takahashi, F., Narusaka, Y., Yamaguchi-Shinozaki, K., Shinozaki, K., 2006. Crosstalk between abiotic and biotic stress responses: current view from the points of convergence in the stress signaling networks. Curr. Opin. Plant Biol. 9, 436-442.

Galmés, J., Medrano, H., Flexas, J., 2007. Photosynthetic limitations in response to water stress and recovery in Mediterranean plants with different growth forms. New Phytol. 175, 81-93.

Granda, V., Cuesta, C., Álvarez, R., Ordás, R., Centeno, M.L., Rodríguez, A., Majada, J.P., Fernández, B., Feito, I., 2011. Rapid responses of C14 clone of Eucalyptus globulus to root drought stress: time-course of hormonal and physiological signaling. J Plant Physiol. 168, 661-670.

Guarnaschelli, A.B., Prystupa, P., Lemcoff, J.H., 2006. Drought conditioning improves water status, stomatal conductance and survival of Eucalyptus globulus subsp. bicostata seedlings. Ann. For. Sci. 63, 941-950.

Guidi, L., Calatayud, A., 2014. Non-invasive tools to estimate stress-induced changes in photosynthetic performance in plants inhabiting Mediterranean areas. Environ. Exp. Bot. 103, 42-52.

Harb, A., Krishnan, A., Ambavaram, M., Pereira, A., 2010. Molecular and physiological analysis of drought stress in Arabidopsis reveals early responses leading to acclimation in plant growth. Plant Physiol. 154, 1254-1271.

Hayat, Q., Hayat, S., Irfan, M., Ahmad, A., 2010. Effect of exogenous salicylic acid under changing environment: a review. Environ. Exp. Bot. 68, 14-25.

Hayat, S., Hasan, S.A., Fariduddin, Q., Ahmad, A., 2008. Growth of tomato (Lycopersicon esculentum) in response to salicylic acid under water stress. J. Plant Interact. 3, 297-304.

ICNF, 2013. $6^{\circ}$ Inventário Florestal Nacional: Áreas dos usos do solo e das espécies florestais de Portugal continental 1995-2005-2010. Resultados preliminares. Lisboa.

Iglesias, G., Wilstermann, D., 2008. Eucalyptus universalis. Global cultivated eucalypt forests map 2008. Version 1.0. 1 In GIT Forestry Consulting's EUCALYPTOLOGICS: Information resources on Eucalyptus cultivation worldwide. http://git-forestry.com/download git eucalyptus map.htm.

Irigoyen, J., Einerich, D., Sánchez-Díaz, M., 1992. Water stress induced changes in concentrations of proline and total soluble sugars in nodulated alfalfa (Medicago sativa) plants. Physiol. Plant. 84, 55-60.

Khan, W., Prithiviraj, B., Smith, D.L., 2003. Photosynthetic responses of corn and soybean to foliar application of salicylates. J. Plant Physiol. 160, 485-492.

Kissoudis, C., van de Wiel, C., Visser, R.G., Van Der Linden, G., 2014. Enhancing crop resilience to combined abiotic and biotic stress through the dissection of physiological and molecular crosstalk. Front. Plant Sci. 5.

Meijón, M., Cañal, M., Fernández, H., Rodríguez, A., Fernández, B., Rodríguez, R. Feito, I., 2011a. Hormonal profile in vegetative and floral buds of Azalea: levels of polyamines, gibberellins, and cytokinins. J. Plant Growth Regul. 30, 74-82.

Meijón, M., Feito, I., Valledor, L., Rodríguez, R., Cañal, M.J., 2010. Dynamics of DNA methylation and Histone $\mathrm{H} 4$ acetylation during floral bud differentiation in azalea. BMC Plant Biol. 10, 10.

Meijón, M., Jesús Cañal, M., Valledor, L., Rodríguez, R., Feito, I., 2011b. Epigenetic and physiological effects of gibberellin inhibitors and chemical pruners on the floral transition of azalea. Physiol. Plant. 141, 276-288.

Merewitz, E., Du, H., Yu, W., Liu, Y., Gianfagna, T., Huang, B., 2012. Elevated cytokinin content in ipt transgenic creeping bentgrass promotes drought tolerance through regulating metabolite accumulation. J. Exp. Bot. 63, 1315-1328.

Mishra, M., Prakash, V., 2014. Impact of foliar application of salicylic acid on growth and lipid peroxidation in water stress tolerance of Glycine max (L.) Merrill. Int. J. Bioassays 3, 1721-1728.

Mohammadkhani, N., Heidari, R., 2008. Drought-induced accumulation of soluble sugars and proline in two maize varieties. World Appl. Sci. J. 3, 448-453.

Naidoo, R., Ferreira, L., Berger, D.K., Myburg, A.A., Naidoo, S., 2013. The identification and differential expression of Eucalyptus grandis pathogenesis-related genes in response to salicylic acid and methyl jasmonate. Front. Plant Sci. 4.

Novák, O., Hauserová, E., Amakorová, P., Doležal, K., Strnad, M., 2008. Cytokinin profiling in plant tissues using ultra-performance liquid chromatographyelectrospray tandem mass spectrometry. Phytochemistry 69, 2214-2224.
Osaki, M., Shinano, T., Tadano, T., 1991. Redistribution of carbon and nitrogen compounds from the shoot to the harvesting organs during maturation in field crops. Soil Sci. Plant Nutr. 37, 117-128.

Pan, X., Welti, R., Wang, X., 2008. Simultaneous quantification of major phytohormones and related compounds in crude plant extracts by liquid chromatography-electrospray tandem mass spectrometry. Phytochemistry 69, 1773-1781.

Parida, A.K., Dagaonkar, V.S., Phalak, M.S., Umalkar, G., Aurangabadkar, L.P., 2007. Alterations in photosynthetic pigments, protein and osmotic components in cotton genotypes subjected to short-term drought stress followed by recovery. Plant Biotechnol. Rep. 1, 37-48.

Pastor, A., López-Carbonell, M., Alegre, L., 1999. Abscisic acid immunolocalization and ultrastructural changes in water-stressed lavender (Lavandula stoechas L.) plants. Physiol. Plant. 105, 272-279.

Pila, N., Gol, N., Rao, T., 2010. Effect of post harvest treatments on physicochemical characteristics and shelf life of tomato (Lycopersicon esculentum Mill.) fruits during storage. American-Eurasian J. Agric. Environ. Sci. 9, 470-479.

Pinheiro, C., Chaves, M., 2011. Photosynthesis and drought: can we make metabolic connections from available data? J. Exp. Bot. 62, 869-882.

Pospíšilová, J., Synková, H., Rulcová, J., 2000. Cytokinins and water stress. Biol. Plant. 43, 321-328.

Potts B.M., Vaillancourt R.E., Jordan G., Dutkowski G.W., McKinnon G., Steane D. Volker P., Lopez G.A., Apiolaza L.A., Li Y., Marques C., Borralho N.M.G., Costa e Silva J. (2004). Exploration of the Eucalyptus globulus gene pool. In IUFRO Conference Eucalyptus in a Changing World, Aveiro.

Pustovoitova, T., Drozdova, I., Zhdanova, N., Zholkevich, V., 2003. Leaf growth, photosynthetic rate, and phytohormone contents in Cucumis sativus plants under progressive soil drought. Russ. J. Plant Physiol. 50, 441-443.

Ran, L.-X., Gu, W.-Z., Wu, G.-J., 2004. Role of Salicylic acid in induction of resistance against bacterial wilt in Eucalyptus urophylla and changes of peroxidase and polyphenol oxidase. For. Res. 1, 003.

Rice-Evans, C., Miller, N., Paganga, G., 1997. Antioxidant properties of phenolic compounds. Trends Plant Sci. 2, 152-159.

Rivas-San Vicente, M., Plasencia, J., 2011. Salicylic acid beyond defence: its role in plant growth and development. J. Exp. Bot. 62, 3321-3338.

Rivero, R.M., Gimeno, J., Van Deynze, A., Walia, H., Blumwald, E., 2010. Enhanced cytokinin synthesis in tobacco plants expressing PSARK:: IPT prevents the degradation of photosynthetic protein complexes during drought. Plant Cell Physiol. 51, 1929-1941.

Rivero, R.M., Shulaev, V., Blumwald, E., 2009. Cytokinin-dependent photorespiration and the protection of photosynthesis during water deficit. Plant Physiol. 150, 1530-1540.

Rosa, M., Prado, C., Podazza, G., Interdonato, R., González, J., Hilal, M., Prado, F., 2009. Soluble sugars-metabolism, sensing and abiotic stress. Plant Signal Behav. 4, 388-393.

Sarafraz-Ardakani, M.-R., Khavari-Nejad, R.-A., Moradi, F., Najafi, F., 2014. Abscisic acid and cytokinin-induced osmotic and antioxidant regulation in two droughttolerant and drought-sensitive cultivars of wheat during grain filling under water deficit in field conditions. Notulae Sci. Biol. 6, 354-362.

Schindelin, J., Arganda-Carreras, I., Frise, E., Kaynig, V., Longair, M., Pietzsch, T., Preibisch, S., Rueden, C., Saalfeld, S., Schmid, B., 2012. Fiji: an open-source platform for biological-image analysis. Nat. Methods 9, 676-682.

Shakirova, F.M., Sakhabutdinova, A.R., Bezrukova, M.V., Fatkhutdinova, R.A., Fatkhutdinova, D.R., 2003. Changes in the hormonal status of wheat seedlings induced by salicylic acid and salinity. Plant Sci. 164, 317-322.

Silim, S., Nash, R., Reynard, D., White, B., Schroeder, W., 2009. Leaf gas exchange and water potential responses to drought in nine poplar (Populus spp.) clones with contrasting drought tolerance. Trees 23, 959-969.

Silva, F., Shvaleva, A., Maroco, J., Almeida, M., Chaves, M., Pereira, J., 2004. Responses to water stress in two Eucalyptus globulus clones differing in drought tolerance. Tree Physiol. 24, 1165-1172.

Sims, D.A., Gamon, J.A., 2002. Relationships between leaf pigment content and spectral reflectance across a wide range of species, leaf structures and developmental stages. Remote Sens. Environ. 81, 337-354.

Singh, B., Usha, K., 2003. Salicylic acid induced physiological and biochemical changes in wheat seedlings under water stress. Plant Growth Regul. 39, 137-141.

Singleton, V., Rossi, J.A., 1965. Colorimetry of total phenolics with phosphomolybdic-phosphotungstic acid reagents. Am. J. Enol. Vitic. 16, 144 158.

Stoparić, G., Maksimović, I., 2008. The effect of cytokinins on the concentration of hydroxyl radicals and the intensity of lipid peroxidation in nitrogen deficient wheat. Cereal Res. Commun. 36, 601-609.

ter Braak, C., Verdonschot, P., 1995. Canonical correspondence analysis and related multivariate methods in aquatic ecology. Aquat. Sci. 57, 255-289.

Volker, P., Greave, B., 2005. Silvicultural management of eucalypt plantations for solid wood and engineered wood products-experience from Tasmania. In Proceedings of the international conference on plantation eucalyptus: challenge in product development, Zhanjiang, pp 1-9.

Wang, Y.H., Irving, H.R., 2011. Developing a model of plant hormone interactions. Plant Signal. Behav. 6, 494-500.

White, D.A., Crombie, D.S., Kinal, J., Battaglia, M., McGrath, J.F., Mendham, D.S. Walker, S.N., 2009. Managing productivity and drought risk in Eucalyptus globulus plantations in south-western Australia. For. Ecol. Manage. 259, 33-44.

Xie, Z., Zhang, Z.-L., Hanzlik, S., Cook, E., Shen, Q., 2007. Salicylic acid inhibits gibberellin-induced alpha-amylase expression and seed germination via a

828 
pathway involving an abscisic-acid-inducible WRKY gene. Plant Mol. Biol. 64, 293-303.

Xu, Z.Z., Zhou, G.S., 2006. Combined effects of water stress and high temperature on photosynthesis, nitrogen metabolism and lipid peroxidation of a perennial grass Leymus chinensis. Planta 224, 1080-1090.
Yamada, H., Suzuki, T., Terada, K., Takei, K., Ishikawa, K., Miwa, K., Yamashino, T., Mizuno, T., 2001. The Arabidopsis AHK4histidine kinase is a cytokinin-binding receptor that transduces cytokinin signals across the membrane. Plant Cell Physiol. 42, 1017-1023. 